\title{
A Foam Pilot Test Aimed at Reducing Gas Inflow in a Production Well at the Oseberg Field
}

\author{
Aarra M. G., Skauge A., Soegnesand S., Stenhang M.
}

\author{
Norsk Hydro a. s., Norway
}

\begin{abstract}
Copyright 1996, Ste日ring Committes of the European IOR - Symposium,
This paper was presented at the 8th. European IOR - Symposium in Vienna, Austria, May 16 - 17,1996

This paper was selected for presentation by the Steering Committee, following review of information contained in an abstract

submitted by the author(s). The paper, as presented hes not been reviewed by the Steering Committee.
\end{abstract}

\begin{abstract}
In June 1994 a foam pilot test was performed in a production well at the Oseberg field, North Sea. The Oseberg field is developed by updip gas injection and are currently experiencing gas breakthrough in some of the production wells. The objectives of the foam test were to obtain field experience of foam placement and foam generation in a production well and to evaluate if foam can be used to reduce gas production due to gas coning. The production well B-27 is located in the Gamma structure and produces from the Oseberg formation, a high permeable (2-3 Darcy) homogeneous sandstone. B-27 is perforated in 5 intervals in the lower section of the Oseberg formation. To evaluate the gas blocking effect of foam within a short time frame and to increase accuracy in measurements only the top perforation interval of B-27 was open for foam treatment and backproduction. The foam was generated by slug-injection of gas and surfactant dissolved in seawater.
\end{abstract}

Gas-oil ratio was reduced with about $50 \%$ after foam placement, compared to production tests prior to foam treatment. The foam pilot-test in production well B-27 was operationally successful. The test has shown that foam can be generated by slug injecting gas and surfactant solution and that foam can reduce GOR even in zones with high oil influx.

The foam treatment proved to be effective in reducing gas inflow over the six month duration of the pilot test.

\section{Introduction}

Many North Sea oil fields produced by gas injection are now in the phase of production where gas breakthrough either has occurred or is expected in the near future. Gas handling may put restrictions on oil production rate from wells, and there is additional cost associated with processing of large gas volumes. One approach to reduce gas inflow due to coning is placement of a foam region around the production well. This concept was investigated in a foam field test in a production well at the Oseberg field in June 1994.

The Oseberg field is located in the Norwegian sector of the North Sea in block 30/6 and 30/9, some $140 \mathrm{~km}$ west of Bergen. Hydrocarbons are trapped in three major tilted fault blocks: Alfa, Alfa North, and Gamma. Gas caps exist in all three structures. The structural dip is an average of 6-10 degrees. The reservoirs belong to the Middle Jurassic Brent Group: Oseberg, Rannoch, Etive, Ness and Tarbert formation. The field contains about $500 \times 10^{6} \mathrm{Sm}^{3}$ of oil and $60 \times 10^{9} \mathrm{Sm}^{3}$ of free gas located in seven partly communicating reservoirs.

In the Oseberg field gas injection is stabilised in the dipping reservoir formation by injecting the hydrocarbon gas updip at gravity stable rates. Gas breakthrough was observed in some of the production wells in the Oseberg field in 1992-1994 and the production well 30/9 - B-27 was selected as candidate for a foam field test. 
Reduction of gas inflow into production wells due to gas coning by injection of foam is a new EOR method for North Sea oil reservoirs. In fact, to our knowledge, there have only been two reported field applications of foam to reduce gas production in production wells ${ }^{1,2}$. Bain et al. ${ }^{1}$ investigated if foam could be used to increase oil production at Prudhoe Bay. They investigated different foam generation methods for production well treatments. Pregeneration of foam at the surface prior to injection was the only method that gave a significant rectuction in gas-oil ratio, while in-situ generation of foam failed to reduce gas inflow.

In this paper we will describe the condition of the well B-27, the injection. scheme, the chemical system chosen for the foam treatment and the gas-oil ratio development prior to and after foam treatment. The well was monitored by a production logging tool (PLT) during injection and start of back-production after foam placement. The production data has been analysed by history matching using a foam mechanistic simulation model.

\section{Well History}

Production well 30/9-B-27 is located in the Gamma structure in the Oseberg field. The well was put on production in December 1988. In the period 1988 until January 1993, B-27 was producing at an average rate of about $5000 \mathrm{Sm}^{3} / \mathrm{D}$ with a gas-oil ratio (GOR) of about $140 \mathrm{Sm}^{3} / \mathrm{Sm}^{3}$. The production rate was then gradually reduced to $2500 \mathrm{Sm}^{3} / \mathrm{D}$. In January 1994 a gas breakthrough was observed in B-27. A TDT (thermal decay time) log run performed on January 28 indicated that the position of the gas-oil contact (GOC) in B-27 was 7 mTVD above the top of the upper perforation interval. It was decided to perform the foam test before the gas had reached the perforations. The well is perforated in 5 intervals in the lower section of the high permeable, homogeneous Oseberg formation. The upper perforation interval has contributed with approximately $34 \%$ of the oil production based on analysis of PLT data. The size of the upper perforation interval is $6,9 \mathrm{mTVD}$ or $9 \mathrm{mMD}$. Table 1 contains events in 1994 occurring after observation of gas breakthrough.

From January 1994 until June 9, when the foam pilot was performed, several production tests monitoring the producing GOR development was performed. The main purposes were to obtain a reference GOR development prior to the foam test and to calibrate the simulation model to be able to extrapolate simulations for comparison to GOR after foam treatment.

Table 1. Well B-27 history, foam treatment

\begin{tabular}{|c|c|}
\hline Date & event \\
\hline 14.01 .94 & Ges breakthrough observed in 30/9-B-27. \\
\hline 28.01 & $\begin{array}{l}\text { Gas-oil contact measured to } 7 \text { mTVD above } \\
\text { upper perforation interval. }\end{array}$ \\
\hline $17.02-07.04$ & $\begin{array}{l}\text { Gas-oil ratio monitoring, oil rate } 2500 \mathrm{Sm}^{3} / \mathrm{D} \text {. } \\
\text { Production from all perforations. }\end{array}$ \\
\hline 08.04 & $\begin{array}{l}\text { Installation of plug below upper perforation } \\
\text { interval. }\end{array}$ \\
\hline $09.04-08.06$ & $\begin{array}{l}\text { Several production tests performed in } 30 / 9 \text {, } \\
\text { B-27. Only top perforation open for production. }\end{array}$ \\
\hline & Oil rate $\approx 600 \mathrm{Sm}^{3} / \mathrm{D}$ \\
\hline $\begin{array}{l}09.06 \\
10.06\end{array}$ & $\begin{array}{l}\text { Start of foam treatment, injection of surfactant } \\
\text { solution and gas. } \\
\text { Stert of beckproctuction after placement of }\end{array}$ \\
\hline 10,010 & toam. Oll rale $\approx 600 \mathrm{sm}^{3} / \mathrm{D}$ \\
\hline
\end{tabular}

In order to better understand the process and to evaluate the efficiency of foam to reduce the GOR in the well within a short time frame, only the top perforation interval was open for foam treatment and backproduction. A plug was therefore installed below the upper perforation interval on April 8, 1994. The GOR development due to only having the upper perforation interval open has been carefully examined.

\section{GOR development prior to foam test}

After a plug isolated production to the top perforation interval several backproduction tests were initiated to observe GOR development during gas coning. In between each production test the well was shut in to allow the gas cone to withdraw. A water injection test was conducted as part of the preparations before the foam injection. Injection of water led to sand production in the well and a sand clean up had to be initiated.

The effects of installing a plug below the upper perforation interval, shut-in period, injection of seawater and clean-out of sand on GOR was investigated. From these production tests a reference GOR curve was established in order to compare GOR development prior to and after foam generation.

Figure 1 shows, GOR development prior to foam injection. The three production test periods April $10-22$, May $10-13$ and June 7-8 have been used to establish the reference curve. After four days of 
production the gas-oil ratio was $\approx 900 \mathrm{Sm}^{3} / \mathrm{Sm}^{3}$. The oil rate during the production tests was approximately $600 \mathrm{Sm}^{3} / \mathrm{D}$. The bottomhole well pressure was fairly constant during backproduction, for this reason the wellhead pressure reflect the density of the fluids in the tubing. A correlation between wellhead pressure and GOR from the test separator is expected, and helps in interpolating GOR measurements in between test separator measurements. For all these test periods the same correlation between wellhead pressure and gas-oil ratio were observed (Fig. 2).

Prior to the foam test we also injected $40 \mathrm{Sm}^{3}$ of seawater (no surfactant) to investigate the effect of seawater on the gas-oil ratio development. A GOR reduction of $150-200 \mathrm{Sm}^{3} / \mathrm{Sm}^{3}$ was observed during backproduction after injection of seawater. This was somewhat surprising as we did not expect a significant change in GOR as a result of injection of seawater. Production logging in B-27 just prior to foam injection showed that sand had been accumulated in the well and that 6 of $9 \mathrm{mMD}$ of the perforation interval was covered by sand. This led to the decision of increasing the oil rate on backproduction to $1800 \mathrm{Sm}^{3} / \mathrm{D}$ to try to produce the sand out of the well. After one day of production at this rate, the sand was displaced from the well. The well was shut-in for one day and than started up again at an oil rate of $600 \mathrm{Sm}^{3} / \mathrm{D}$ to establish the gas-oil ratio development just prior to the foam test. Tagging of the well showed no additional sand accumulation during the production period after sand clean out.

In Figure 2 the correlation between wellhead pressure and gas-oil ratio for all productions tests prior to the foam test is shown. As seen from Figure 2 , the only production test that does not fit the correlation between the wellhead pressure and the gas-oil ratio is the backproduction after injection of seawater. The accumulation of sand appears to influence the distribution of oil and gas in the tubing column. The different correlation between WHP and GOR after injection of seawater make it difficult to interpret the GOR development after injection of seawater when compared to the other production tests performed in B-27.

The GOR development just prior to injection of seawater (May 10-13) and the GOR development after sand cleanup (June 7-8) are compared in Figure 3 . The two GOR curves are nearly identical and, together with the GOR/WHP correlation, give evidence for restored well properties after sand clean-up prior to the foam test. Due to reduced offtake from the Gamma structure in May 94 it is anticipated that the gas-oil contact was fairly constant during May, which is also indicated in Figure 3. A stagnant gas front was also incorporated in the simulation history match for the period of May 1994.

The position of the sand contact above the plug was measured twice after removal of sand. On June 9th, prior to injection of surfactant solution and gas, the oil - sand contact was measured to $3347 \mathrm{mMD}$ RKB. Only $1 \mathrm{mMD}$ of the perforation interval was at this time covered by sand. On June 11, 18 hours after start of backproduction after foam generation, the oil - sand contact was measured to 3347,5 mMD RKB. This indicate that injection of surfactant solution and gas did not give additional sand production.

\section{Accuracy in measurements}

Oil rate. It may be difficult to obtain accurate measurement of the oil rate from the test-separator at low oil production rates. To secure accuracy in the measured oil rate a Halliburton turbine meter was therefore installed at the test separator oil outlet line in series with the oil meter. The turbine meter was calibrated at representative rates and the grade of accuracy, according to the vendor, was \pm $1 \%$. The oil rates measured on the standard oil meter on the test separator, after setting of plug, have been monitored and thereafter: adjusted according to the oil rate observed on the Halliburton turbine meter. The oil rate measurements at the test-separator varied at different backproduction periods compared to the Halliburton turbine meter, but was constant within each flow period. Installation of the turbine meter was a necessary improvement to obtain confidence in the data collected.

Gas rate. Based on earlier experience from several tests, gas injection routed through the test-separator has shown an average accuracy of $2-3 \%$ in the gas rate measurements. Even though the gas rate during these tests has been higher (gas rate $=30-80$ $\mathrm{kSm}^{3} \mathrm{~h}$ ) than in the production testing of well B-27 (gas rate $\approx 11 \mathrm{kSm}^{3} / \mathrm{h}$ ), it is anticipated that the accuracy in the gas rate measurements during the production testing were within $5 \%$. The same equipment to measure gas rates was used during the B-27 production tests both prior to foam treatment and after placement of foam. 


\section{Operational procedure}

The foam test performed in Oseberg well B-27 was the first evaluation of foam for a North Sea reservoir application. In that sense the foam test aimed at giving valuable information about several aspects of offshore foam placement in high temperature and high pressure reservoirs, ranging from injection procedure to evaluation of GOR development after foam treatment.

Injection set-up. During the planning of the foam test in B-27 different procedures for injection of surfactant solution, seawater and gas were investigated. The method selected used the water injection manifold, gas routed from the injector line and the wellhead kill system in order to displace the fluids into well B-27. During surfactant/seawater and gas injection a PLT was installed to monitor the downhole fluid density, pressure, and local flow rate. The PLT gave information about what fluid was injected at the perforations.

Injection of seawater was obtained by mounting a flexible hose from the water injection manifold to the choke together with a meter in which the water injection rate was measured. Both seawater and surfactant solution was injected through the kill system. The volumes injected were arranged to give either $2 \%$ or $1 \%$ surfactant concentration in the solution injected into the reservoir. Surfactant was injected using a chemical pump skid. The pump delivery was calibrated continuously to ensure accuracy of the surfactant injection rate.

Gas was routed across a neighbour well, before entering the choke. Display for measurement of gas injection rate and gas volume was installed at the choke. A V-cone meter was used for gas measurements. Temperature, pressure and differential pressure were processed in a Mastrol flow computer tuned for the specific gas composition.

The equipment used to inject seawater and gas was tested during the water injection performed May 22, 1994. Both injection of seawater and gas (drive fluid for water) were according to planned and no adjustments were required prior to the foam test. Delivery of surfactant solution proved to be stable at specified concentration even though the surfactant solution had a viscosity of $92 \mathrm{mPa} \mathrm{s}$ (centipoise) at $25^{\circ} \mathrm{C}$. The injection procedure will be recommended for future foam treatments.

\section{Surfactant}

During 1993 and 1994 a large effort has been carried out in order to qualify a foam system suitable for the foam test. The main purpose of this study was to identify at least one system stable at Oseberg reservoir temperature and pressure, respectively $100^{\circ} \mathrm{C}$ and $280 \mathrm{bar}$. The results of this study has been discussed in a previous paper ${ }^{3}$. In the field test an alpha olefin sulfonate (AOS) from Albright and Wilson (LSS 38/AS) was used. This surfactant generated strong foams both at in-situ generation and by injection of pregenerated foam. The results indicated further that the surfactant has a good tolerance to residual oil both at $S_{\text {org }}$ and $\mathrm{S}_{\mathrm{orw}}{ }^{3}$.

The solubility properties of the surfactant showed that $1 \%$ AOS dissolved in synthetic seawater precipitated at $10^{\circ} \mathrm{C}$. AOS, as delivered from the manufacture did not precipitate even at $5{ }^{\circ} \mathrm{C}$. It was possible to maintain a temperature of $22-24{ }^{\circ} \mathrm{C}$ on the injected seawater and it is likely that surfactant precipitation did not arise during the injection sequences.

\section{Injection of fluids}

How to create and place foam in the optimum position in the reservoir are important parts of the gas blocking process. Foam could either be injected as a premixed foam or formed in the reservoir. For the foam test in B-27 four different generation methods for foam were considered ${ }^{3}$.

The alternating slug injection method was selected for the reasons of securing good injectivity and deep emplacement of the foam. Generation of a strong foam was intended by reducing the slug size of gas and surfactant solution at the end of the injection sequence. The slug injection procedure has recently. been applied successfully in $\mathrm{CO}_{2}$ foam field trials ${ }^{4}$. It was decided to inject a volume of surfactant solution in order to treat a distance $\leq 10 \mathrm{~m}$ away from the wellbore. Any further extension of the treated area was not recommended to avoid excessive surfactant backproduction into the separator system.

The injection rate of the fluids were supposed to be evaluated during test operations. The main purpose was to reduce slug size of surfactant solution and gas successively to ensure generation of foam. Originally, the plan was to inject 6 sequences each of surfactant solution and gas. First, a large slug of a $2 \%$ surfactant should be injected in order to take 
care of adsorption. Then, the slug-size of surfactant solution was reduced with $50 \%$ followed by gas to give a foam quality of $65 \%$ (volume fraction of gas) for each cycle. This would have given almost co-injection of surfactant solution and hydrocarbon gas at the end of the injection sequence. If the pressure build-up increased severely, the test was intended to stop as it was taken as a sign of foam generation. Below the actual injection strategy used offshore is described.

Offshore preparation for injection of foam was started on June 9, 1994. The test started by displacing the fluid in the well with gas. Hydrocarbon gas was injected at a rate of approximately $9400 \mathrm{Sm}^{3}$ hour and the total volume of gas injected was $5340 \mathrm{Sm}^{3}$. By using the density measurement on the PLT we determined what phase was injected into the reservoir after start of injection of surfactant solution and seawater. In Table 2 the actual volumes injected of surfactant solution, seawater and gas are given.

The injection of seawater and surfactant solution was performed at a total rate of $6 \mathrm{Sm}^{3}$ /hour during the first 1.5 hours of injection. Thereafter the rate was increased to $12 \mathrm{Sm}^{3}$ hour. Increased injection rate reduced the segregation of water in the reservoir zone. The first slug of water and surfactant solution contained a surfactant concentration of $1.8 \mathrm{wt} \%$. The high surfactant concentration in this slug aimed at taking care of adsorption and still contain enough surfactant to generate strong foam. During the injection of surfactant solution and seawater the density measurement on the PLT indicated that very little surfactant solution/seawater, if any, had been injected into the reservoir. The injection density measurements indicated that only gas located in the well at the start of injection of surfactant solution and water had entered the reservoir.

The PLT was then moved upwards in order to establish the density profile in the well, Figure 4. Several intervals of high density was discovered and both density measurements and WHP indicated that liquid did not enter the reservoir. That is, approximately $65 \mathrm{Rm}^{3}$ of hydrocarbon gas had been injected. The segregation velocity for seawater and surfactant solution was much slower than expected. In fact, from density measurements in the well at different times, it was calculated to move only 1.3 $m$ along tubing length pr. minute. The well was therefore closed for 8 hours to accumulate the water phase at the bottom of the well before entering the reservoir. Gas positioned in the near wellbore area may influence the liquid distribution close, to the well. The time needed for water to segregate down to the perforation interval made it impossible to alternate the slug of surfactant solution and gas as planned. Therefore the surfactant was only injected in two slugs. Gas was used as driving fluid during injection of surfactant seawater solution and after gas had reached the perforation some additional gas was injected in order to generate foam. The surfactant concentration in the last part of the second injection was $1 \%$.

A pressure build-up of approximately 2 bar was obtained during the first injection sequence. Figure 4 shows the PLT density profile versus depth at different time during the shut-in periods.

\section{GOR development after foam injection}

Well 30/9-B-27 was put on production 1.5 hours after foam injection was ended. The idea was to make the shut-in period after completing the injection sequence as short as possible both to prevent segregation of surfactant solution and to use gas from the gas cone to generate foam. The production testing of well B-27 prior to foam injection had shown that a gas cone was established quickly.

The well was originally planned to be produced at an oil rate of approximately $300 \mathrm{Sm}^{3} / \mathrm{D}$ during the start of backproduction after foam injection. After a few hours the oil rate should be increased to 600 $\mathrm{Sm}^{3} / \mathrm{D}$ equal to the oil rate during production testing prior to the foam test. In this period there were problems in measuring oil rates as low as 300 $\mathrm{Sm}^{3} / \mathrm{D}$ and the well was produced at an oil rate of approximately $600 \mathrm{Sm}^{3} / \mathrm{D}$ from the start of backproduction. After the shut-in period in the start of July the oil rate has been reduced to approximately $450 \mathrm{Sm}^{3} / \mathrm{D}$. The oil rate was in this time period acoording to measurement specification.

The GOR development after foam injection is shown in Figure 5 and Figure 6. In Figure 5 the GOR development versus hours after start-up is given for the first 38 days of production. In this period the gas-oil ratio was measured frequently. In Figure 6, GOR development versus days after start-up is shown from June 10 to shut-in of well B-27 on January 5, 1995. Both these plots need to be evaluated when interpreting the GOR development after foam injection. 38 days after foam placement $20 \mathrm{Sm}^{3}$ of seawater was injected to 
investigate if additional water could strengthen the gas blocking and possible generate new foam lamellas. The injection of water seemed to have little effect on further reduction of GOR.

Figure 5 also includes, the reference GOR curve obtained during production tests prior to the foam test. When compared to the reference GOR curve a reduction of about $50 \%$ in GOR was achieved by foam. This comparison is conservative in the sense that the gas-oil contact (GOC) has moved further down both until foam injection started and during backproduction after foam injection. After foam injection the same correlation between GOR and WHP was observed as in the periods April 10-22, May 10-13 and June 7-8 used to generate the reference gas-oil ratio curve, Figure 7 .

The plug remained in place throughout the backproduction after foam injection. The lower perforation intervals were isolated both prior to the foam treatment and during production after foam injection. Oil was produced through the same interval as the foam was generated and it is quite impressive that gas inflow in the well was reduced significantly for at least a 6 months period (Figure 6). During the pilot test there has been two major shut-in periods. These were also taken into account when calculating GOR if no foam was present.

It is reasonable to believe that foam efficiency would have been even further improved if the oil flow was mainly from other perforation intervals than the zone where the foam was placed because foam stability can be strongly reduced at high oil saturation. The best condition for gas blocking by foam would be to have other perforation intervals open for oil inflow. The reason why this test was performed on a single top perforation interval was to obtain experience of gas blocking by foam within a short time frame and to improve the accuracy in the measurements.

\section{Foam simulation study}

Simulation show that ideal placed foam, reducing gas relative permeability in a radius of more than $9 \mathrm{~m}$ from the wellbore, could delay the gas breakthrough by $50-100$ days: Blocking of gas by foam may increase the oil production. by $20-100$ $10^{3}$ tons. Further simulations using a compositional simulator with an empirical foam model investigated the sensitivity to foam properties ${ }^{5}$. A 3-D radial model was used to history match the production tests prior to foam injection, and the same model was further applied after foam treatment to generate a reference GOR development and to match the experienced foam effect on GOR. The history match prior to foam showed the necessity to include the movement of the field gas-oil contact. Field $\log$ observations show a frontal gas movement of $1.3 \mathrm{~m} \mathrm{TVD} / \mathrm{month}$.

In Figure 8, history match of the two baseline production periods, April 10-22 and May 10-13, prior to foam treatment is shown. The production GOR after foam placement was compared to the simulated gas fractional flow extrapolated from the history match prior to foam trearment. As seen, the foam reduced the gas inflow over the duration of the backproduction period (Fig. 6/8).

To history match the measured gas-oil ratio development during these production tests the gas-oil contact position was assumed to be $1 \mathrm{~m}$ TVD above upper perforation interval in the start of April 1994. Further details about sensitivity of gas-oil contact position on gas-oil ratio development is given in ref. 5 .

The best match ${ }^{5}$ of the production GOR was achieved in the simulation run with gas mobility reduction by foam equal to 30 and critical surfactant concentration of $1.8 \mathrm{wt} \%$. The tuned empirical foam simulation model seem to match the field GOR development. To compare against the GOR development if foam was not used it was crucial to have the production tests prior to foam as a calibration tool. By history matching these tests a good basis for comparison was established.' The reduction in GOR is more than $50 \%$ due to foam injection, and the effect of foam was maintained during the total pilot period of six months. These results indicate that foam stability or breaking/regenereation of foam lamellas continued for more than half a year.

The chemical cost for the foam pilot was about \$ 10,000 . The low cost of such a process makes this EOR method economical viable. The history match of the pilot was used to further estimate the effect if all the perforation intervals were open during production. Figure 9, compare the scenarios of oil production with and without foam present, and show that also in the case with removal of the isolating plug a strong reduction in GOR could be achieved. 
10 Conclusions

1: The offshore operations of foam injection and backproduction was according to plan, and the same procedures can be recommended for future foam applications. During the injection of surfactant solution and gas neither reduction in injectivity nor formation of hydrate was reported.

2. During backproduction after foam injection approximately $20 \%\left(20 \mathrm{Sm}^{3}\right)$ of seawater was backproduced. No generation of foam in the test separator or in the topside oil process system was observed. Foam generation in the water production system was reported, but the problem was solved without closing well B-27.

3. The test has shown that foam can be generated by slug injecting surfactant solution/seawater and gas, and that foam can reduce GOR in gas coning situations in zones even with high oil influx.

4. Gas-oil ratio development prior to the foam test was a necessary tool for obtaining a reference gas-oil ratio curve to the GOR development after foam treatment.

5. GOR was reduced about $50 \%$ after foam placement compared to production tests prior to foam treatment.

6. Extrapolation of the pilot data to reduce production during gas coning show that production well treatment can be technical viable and have a good economical potential.

\section{Nomenclature:}

Foam quality : Volume gas / volume gas and water

TDT : Thermal Decay Time

PLT : : Production Logging Tool

TVD : True Vertical Depth

MD RKB : Measured Depth Rotary Kelly Bushing

GOR : Gas-Oil Ratio $\left(\mathrm{Sm}^{3} / \mathrm{Sm}^{3}\right)$

WHP : Well-Head Pressure (Bar)

GOC : Gas-Oil Contact

\section{Acknowledgements}

The authors acknowledge Norsk Hydro and the Oseberg license partners, Elf, Mobil, Saga, Statoil and Total for permission to publish this paper. We especially thanks L. M. Surguchev, Rogaland Research, for performing the simulation work.
References:

1. Bain, G.F., Kuehne, D.L., Krause, R.E., and Lane, R.H.: "Foam Treatment of Producing Wells to increase Oil Production at Prudhoe Bay", SPE/DOE 24191, presented at the SPE/DOE Eight Symposium on EOR, Tulsa, Oklahoma, April 22-24, 1992.

2. Heuer G.J., jr. and Jacocks C.L.: U.S. Patent no. $3368624,1968$.

3. Aarra, M. G., and Skauge, A.: "A Foam Pilot in a North Sea Oil Reservoir; Preparation for a Production Well Treatment", SPE 28599, presented at the 69th Annual Technical Conference and Exhibition, New Orleans, LA, Sept. 25-28, 1994.

4. Hoefner, M.L., Evans, E.M., Buckles, J.J., and Jones, T.A.: " $\mathrm{CO}_{2}$ Foam: Results From Four Development Field Trials", SPE/DOE 27787, presented at the SPE/DOE Ninth Symposium on IOR, Tulsa, Oklahoma, April 17-20, 1994.

5. Surguchev, L.M., Søgnesand, S., Skauge, A., and Aarra, M.G.: "Modelling and History Matching of Foam Field Pilot, Oseberg Field", presented at the 8th European Symposium on Improved Oil Recovery, Vienna, Austria, May 15-17, 1995. 
Table 2 Actual injected volumes and rates for the foam test in 30/9-B-27.

\begin{tabular}{|c|c|c|c|c|c|c|}
\hline & VOLUME & INUECTED & (5mi') & RATE & [Ism'hour] & \\
\hline Snquencen & Cosmater & zurteresent & $g 29$ & Easmaner & gurdsectant & gas \\
\hline 1 & & & 5320 & & & 2000 \\
\hline 2 & 9.6 & 0.43 & & 5.7 & 0.3 & \\
\hline 3 & 460 & 2.5 & & 10,4 & 0.6 & \\
\hline 4 & Shall in & a hourn & & & & \\
\hline 5 & & & 15300 & & & 5000 \\
\hline - & 12.35 & 0.8 & & i1.4 & 0.8 & \\
\hline 7 & 30,9 & 0,80 & & 11,4 & 0,3 & \\
\hline 8 & Shut in & o hourt & & & & \\
\hline 。 & & & 14500 & & & 10000 \\
\hline
\end{tabular}

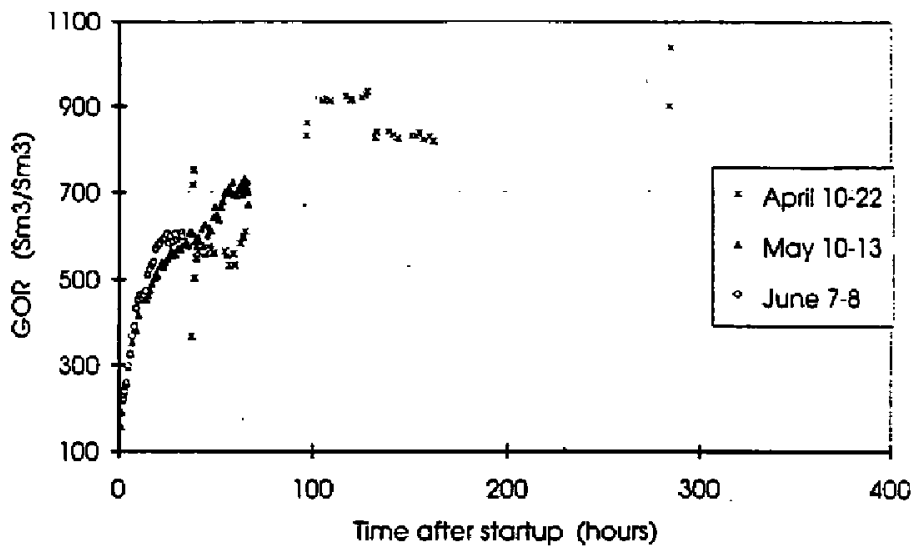

Figure 1 Gas-Oil Ratio development prior to foam test, reference curve.

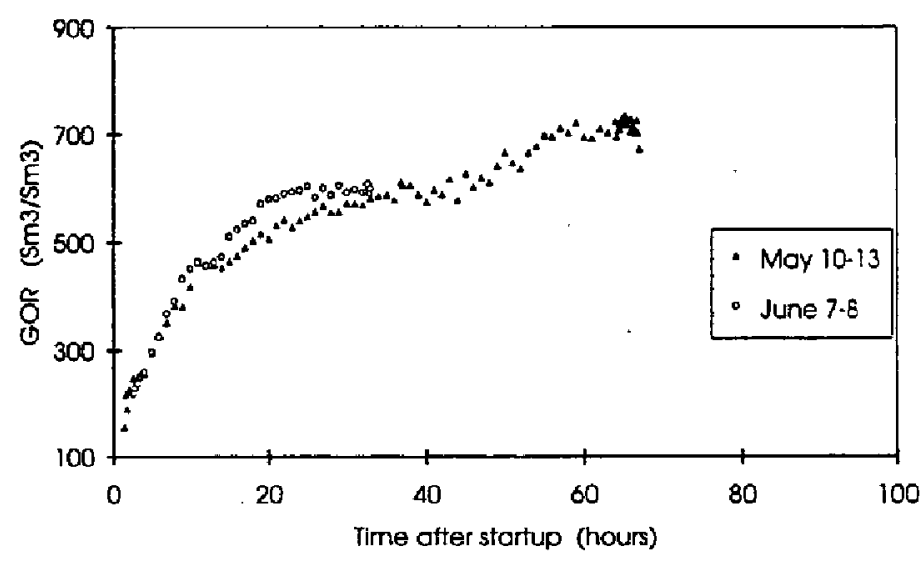

Figure 3 Gas-Oil Ratio vs. bours after start-up, before and after sand cleanout.

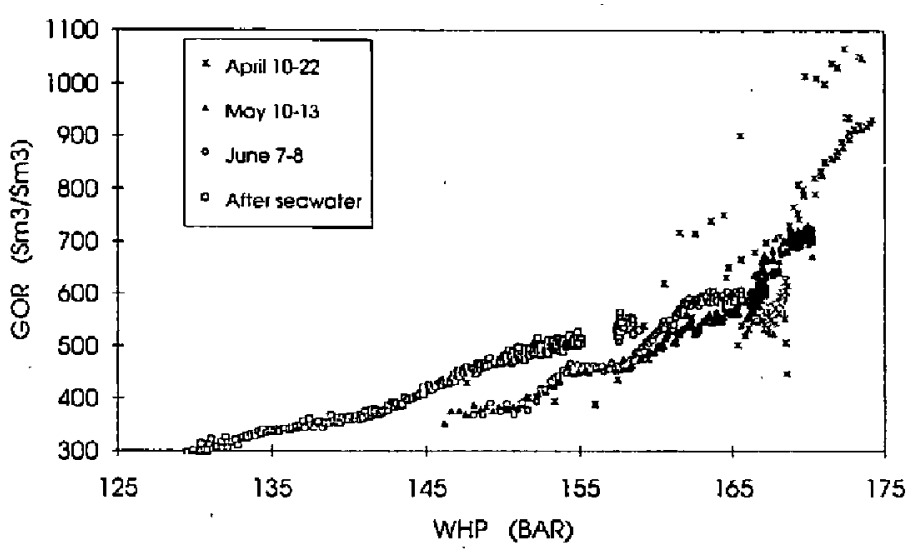

Figure 2 Gas-Oil Ratio vs. Well-Head Pressure for all production tests prior to foam injection.
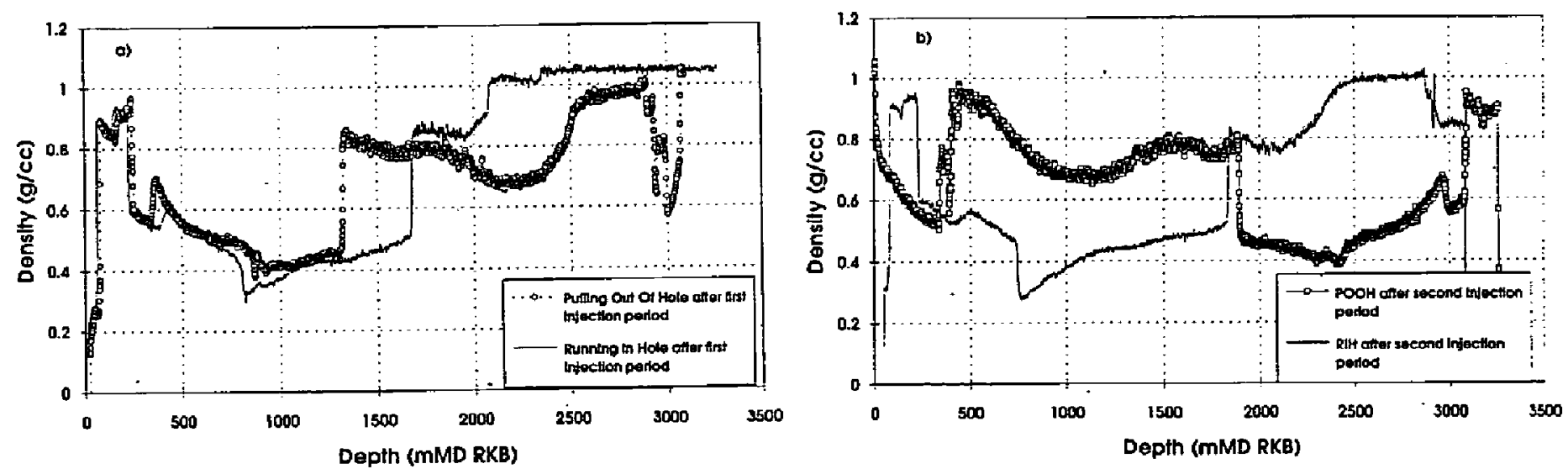

Figure 4 Well density profiles a) after first injection sequence of surfactant solution/seawater and b) after second injection sequence of surfactant solution/seawater. 


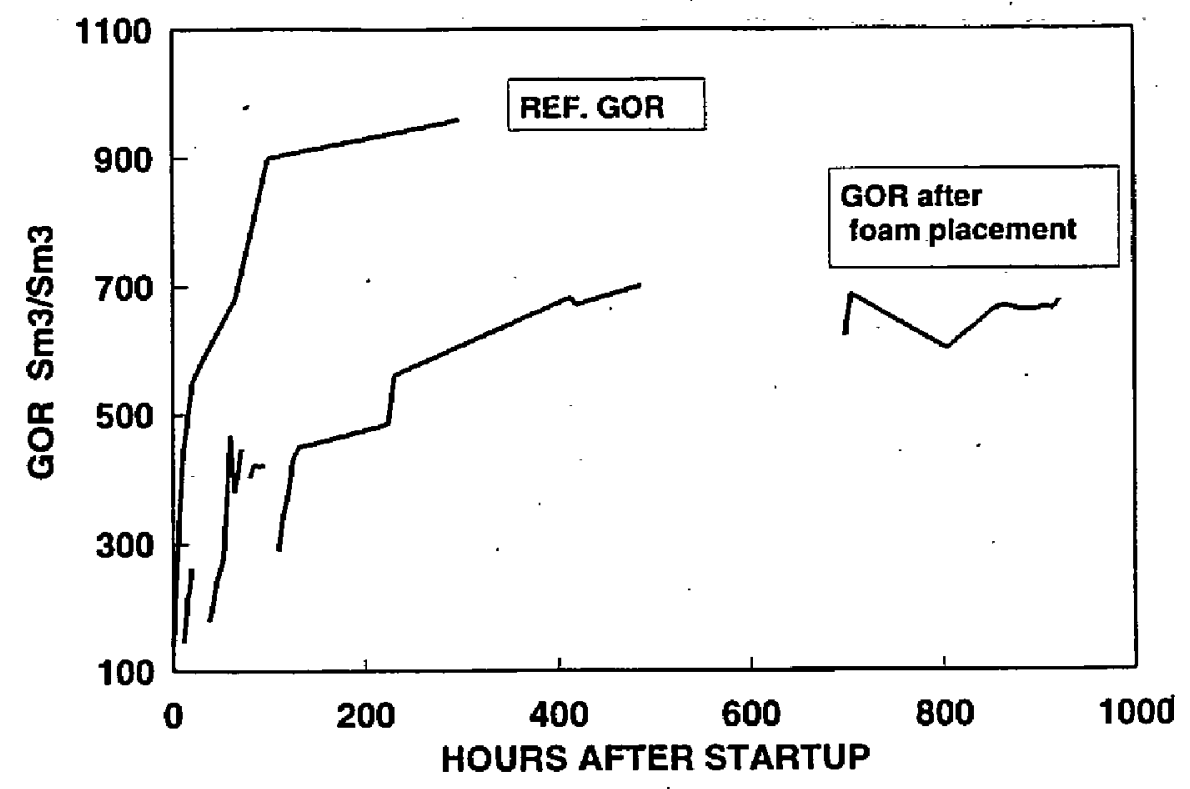

Figure 5 Gas-Oil Ratio development after foam placement (first 38 days).

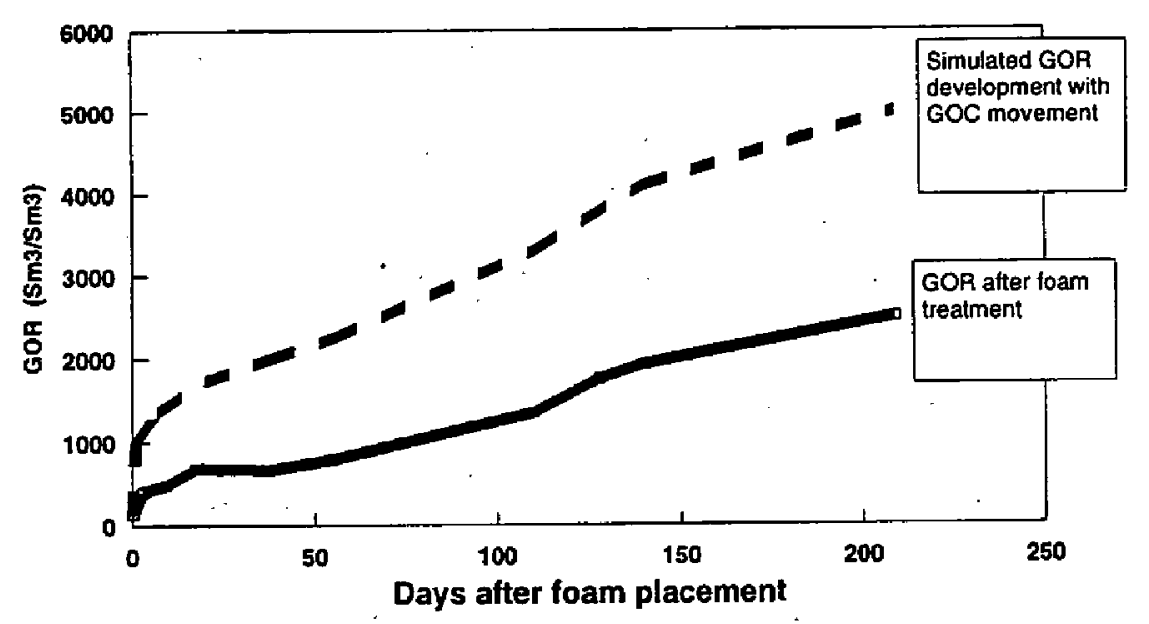

Figure 6 Gas-Oil Ratio development after foam placement vs. days after foam placement.

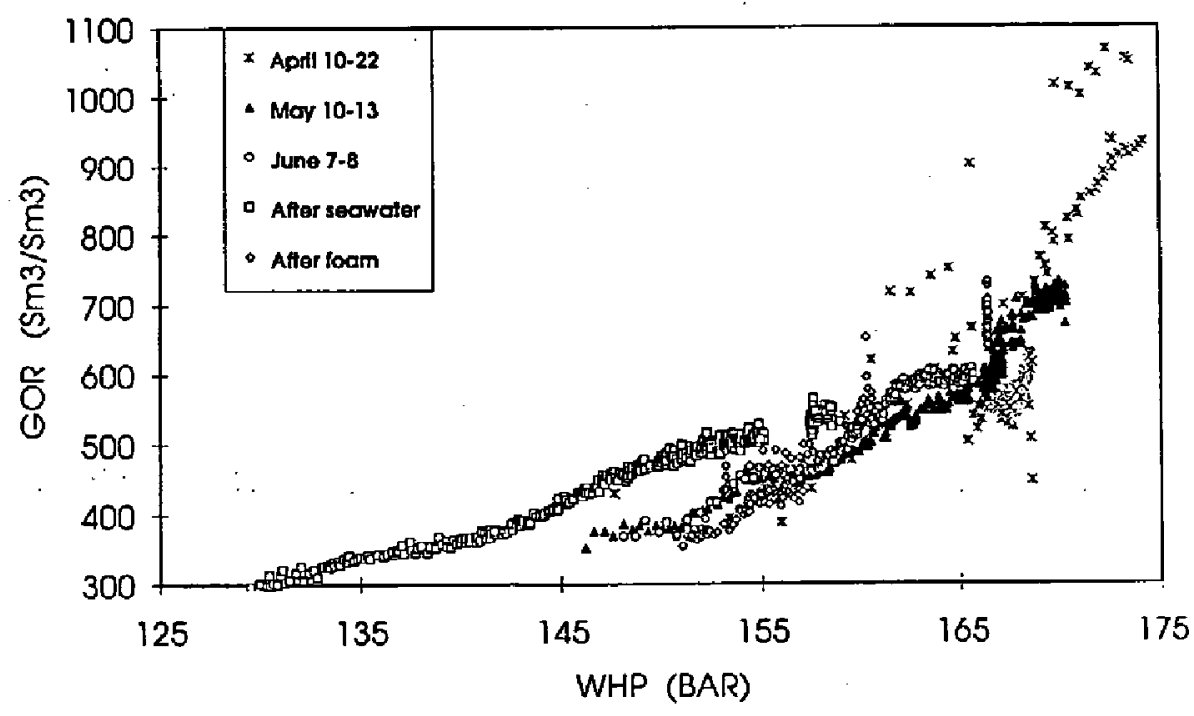

Figure 7 Gas-Oil Ratio vs. Well-Head Pressure for all production tests in well 30/9-B-27. 


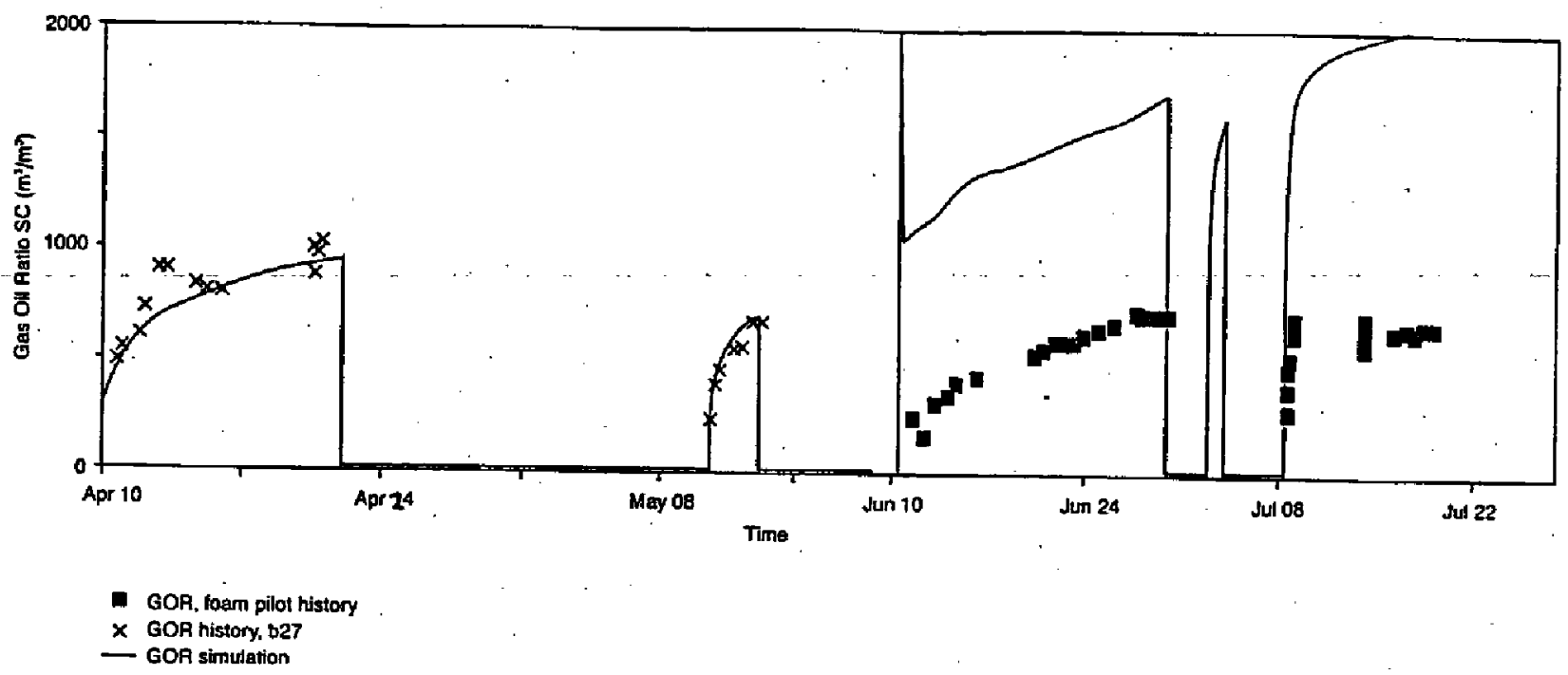

Figure 8 History match of the two baseline production tests (April 10-22, May 10-13), GOR development if no foam was present and observed GOR during the first 38 days after foam placement.

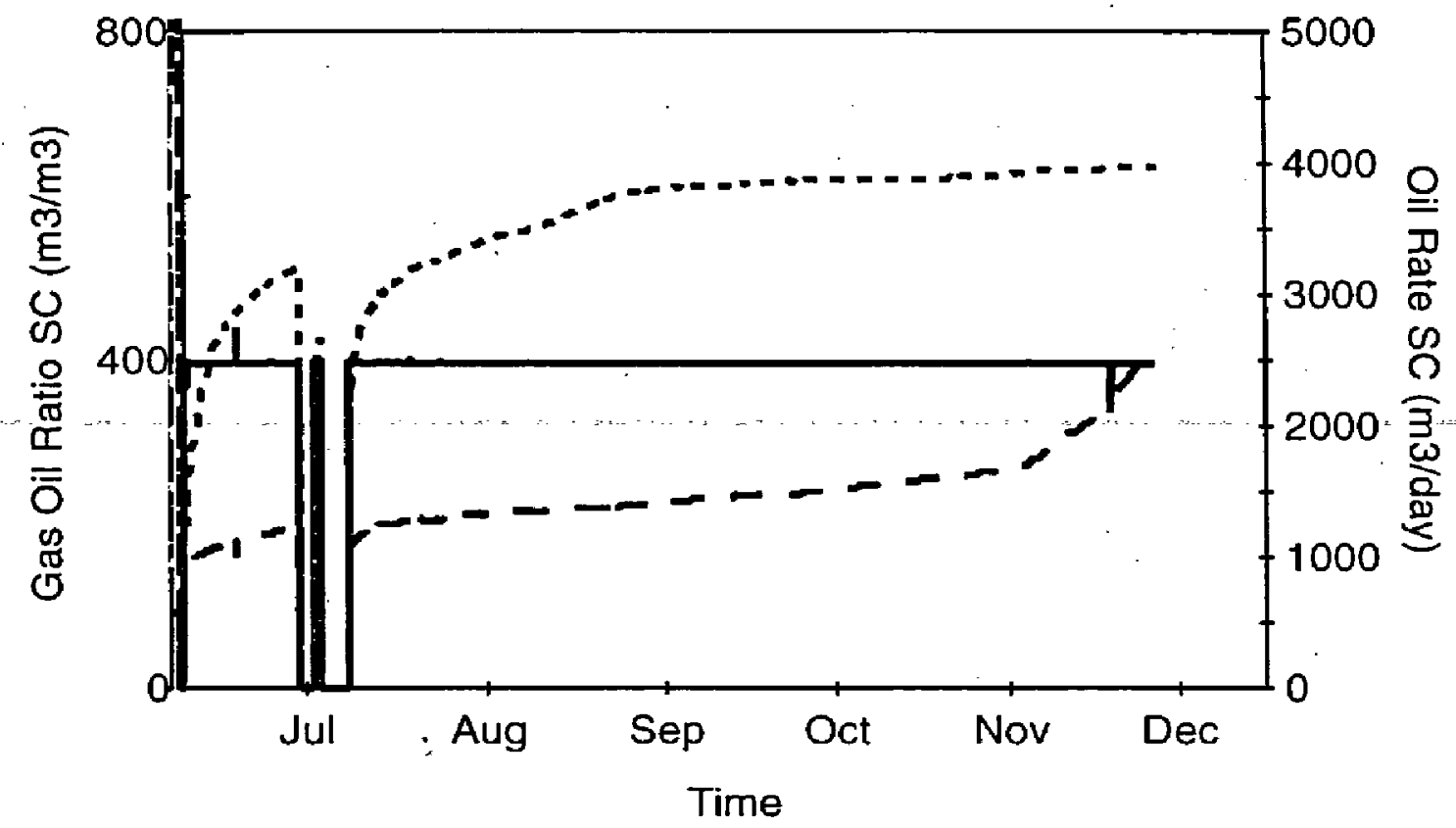

Figure 9 Simulation of foam potential for 30/9-B-27, no plug.

- - - -. GOR - no foam

- - GOR - foam MRF $=30$,

Oil Rate SC - simulation 